\title{
Thoughts and Progress
}

It is the goal of this section to publish material that provides information regarding specific issues, aspects of artificial organ application, approach, philosophy, suggestions, and/or thoughts for the future.

\section{Preparation of Ethanol-Enriched, Bicarbonate-Based Hemodialysates}

\author{
*Abd A. Noghnogh, *Ralston W. Reid, \\ *Zeenat M. Nawab, †Richard D. Swartz, \\ *Carl M. Kjellstrand, and *Todd S. Ing at the \\ *Departments of Medicine and Psychiatry, \\ Veterans Affairs Hospital, Hines, and Stritch School \\ of Medicine, Loyola University Chicago, Maywood, \\ Illinois and †Department of Medicine, University of \\ Michigan School of Medicine, \\ Ann Arbor, Michigan, U.S.A.
}

\begin{abstract}
We describe a method to produce bicarbonatebased dialysates containing $\sim 100 \mathrm{mg} / \mathrm{dl}$ ethanol by introducing the alcohol into one of the dialysate concentrate solutions geared for the production of bicarbonate-based dialysates. Key Words: Ethanol-Bicarbonate-Dialysate-Dialysate concentrate.
\end{abstract}

Received June 1998

Address correspondence and reprint requests to Dr. T.S. Ing, Veterans Affairs Hospital, Hines, Illinois 60141, U.S.A.
Ethanol is used in the treatment of poisonings by methanol or ethylene glycol (1-4). In the event that a patient needs dialysis, ethanol, in addition to being given via the oral or intravenous route, can conveniently be introduced into the dialysate so that a more stable blood ethanol level can be attained $(3,4)$.

Currently, two basic, dual concentrate, bicarbonate-based, proportioning dialysate generating systems are in common use by dialysis units in the U.S.A. Championed by Sargent et al. (5), one of the systems utilizes a base dialysate concentrate solution containing sodium, chloride, and bicarbonate as well as an acid dialysate concentrate solution (Renasol concentrates, Renal Systems, Minneapolis, MN, U.S.A.) containing sodium, potassium, calcium, magnesium, chloride, acetic acid, and glucose. The other system was pioneered by Delin et al. (6) and is characterized by having a sodium bicarbonate powder housed in a cartridge as well as an acid dialysate concentrate solution harboring glucose, acetic acid, and the rest of the constituent electrolytes. In addition, a modification of the Delin system utilizing a sodium bicarbonate dialysate concentrate solution instead of a sodium bicarbonate powder as the source of bicarbonate is also commercially available

TABLE 1. Volume of ethanol-free dialysate concentrate solution and that of absolute alcohol required for the creation of $1 \mathrm{~L}$ of an ethanol-enriched dialysate concentrate

\begin{tabular}{lccc}
\hline $\begin{array}{c}\text { Ethanol-free dialysate } \\
\text { concentrate to be } \\
\text { enriched with ethanol }\end{array}$ & Degree of dilution ${ }^{a}$ & $\begin{array}{c}\text { Volume of dialysate } \\
\text { concentrate }^{b} \\
(\mathrm{ml})\end{array}$ & $\begin{array}{c}\text { Volume of absolute } \\
\text { alcohol }^{c} \\
(\mathrm{ml})\end{array}$ \\
\hline $\begin{array}{l}\text { Sargent method } \\
\text { Acid concentrate }\end{array}$ & $\times 36.83$ & 953.4 & $46.6(36.8)$ \\
Base concentrate & $\times 20.13$ & 974.5 & $25.5(20.1)$ \\
Modified Delin method & $\times 45.00$ & 944.3 & $56.3(45)$ \\
Acid concentrate & $\times 26.14$ & 966.9 & $33.1(26)$ \\
Base concentrate & & & \\
\hline
\end{tabular}

${ }^{a}$ Required for ethanol-enriched dialysate concentrate to become a final dialysate.

${ }^{b}$ Required for the creation of $1 \mathrm{~L}$ of ethanol-enriched dialysate concentrate. Geared for the generation of a dialysate containing approximately $100 \mathrm{mg} / \mathrm{dl}$ ethanol.

${ }^{c}$ Required for creation of $1 \mathrm{~L}$ of ethanol-enriched dialysate concentrate. Geared for the generation of a dialysate containing approximately $100 \mathrm{mg} / \mathrm{dl}$ ethanol. Figures within parentheses represent grams, the specific gravity of absolute alcohol being 0.794 . 
TABLE 2. Ethanol, sodium, and chloride levels in ethanol-enriched hemodialysates

\begin{tabular}{|c|c|c|c|}
\hline $\begin{array}{c}\text { Ethanol-enriched } \\
\text { dialysate } \\
\text { concentrate }^{a}\end{array}$ & $\begin{array}{l}\text { Dialysate ethanol } \\
\text { level }(\mathrm{mg} / \mathrm{dl})\end{array}$ & $\begin{array}{l}\text { Dialysate sodium } \\
\text { level }(\mathrm{m} M)\end{array}$ & $\begin{array}{c}\text { Dialysate chloride } \\
\text { level }(\mathrm{m} M)\end{array}$ \\
\hline \multicolumn{4}{|l|}{ Sargent method } \\
\hline Acid concentrate & 106 & 143 & 110 \\
\hline Base concentrate & 110 & 142 & 110 \\
\hline \multicolumn{4}{|l|}{ Modified Delin method } \\
\hline Acid concentrate & 110 & 143 & 113 \\
\hline Base concentrate & 112 & 143 & 114 \\
\hline
\end{tabular}

${ }^{a}$ Each of the ethanol-enriched dialysate concentrates listed was routed through a dual concentrate, bicarbonate-based, dialysate generating machine in a manner similar to the one utilized in a regular dialysis (including, of course, the simultaneous routing of the respective conjugate ethanol-free member of the dual concentrate pair) to produce the desired ethanol-enriched, bicarbonate-based dialysate.

(Renalyte Rx sodium bicarbonate concentrate, Gambro Healthcare, Lakewood, CO, U.S.A.). To our knowledge there are no detailed studies describing the feasibility of adding ethanol to dialysate concentrates nor of the accuracy of ethanol delivery when these dialysate concentrates are used in conjunction with proportioning dialysate generating machines.

\section{Materials and methods}

In an attempt to determine the feasibility of enriching the previously described dialysate concentrate solutions with ethanol, we introduced absolute alcohol (100\% ethanol, i.e., 200 proof) to each of these solutions in the following manner. An amount of ethanol sufficient to produce (when using a dual concentrate, bicarbonate-based, proportioning dialysate generating machine) a final dialysate possessing approximately $100 \mathrm{mg} / \mathrm{dl}$ ethanol was used. Table 1 describes the quantity of absolute alcohol that had to be added to one of the dialysate concentrates to constitute a liter of an ethanol containing concentrate geared for the production of a bicarbonate-based dialysate having approximately $100 \mathrm{mg} / \mathrm{dl}$ ethanol.

\section{Results}

The results are depicted in Table 2. The planned target ethanol level in the realm of $100 \mathrm{mg} / \mathrm{dl}$ was achieved in all instances.

\section{Discussion}

The use of dialysates enriched with ethanol to dialyze patients suffering from ethylene glycol poisoning was first suggested by Peterson et al. (1). However, previous attempts to enrich dialysates with ethanol have primarily involved the use of batch system dialysates employing acetate-based concentrates (2). To prepare ethanol-enriched, bicarbonate-based dialysates using proportioning, single pass machines, we previously introduced the alcohol into the dialysate inlet of a dialyzer with the use of an infusion pump and a $\mathrm{T}$ tube inserted into the dialysate delivery tubing (3). To circumvent the use of a pump and a $\mathrm{T}$ tube, Wadgymar and $\mathrm{Wu}$ have recently recommended the direct placement of ethanol into the acid concentrate of a dual concentrate, bicarbonate-based, proportioning dialysate generating system (4). Our findings are in agreement with those obtained by these authors. However, we have also demonstrated that ethanol can be directly and safely introduced not only into 2 currently available varieties of base dialysate concentrates, but also into their respective conjugate acid dialysate concentrates for the purpose of ethanol enrichment.

\section{References}

1. Peterson CD, Collins AJ, Keane WF, Himes JM. Ethanol for ethylene glycol poisoning (letter). N Engl J Med 1981;304: 977 .

2. Swartz RD, Millman RP, Billi JE, Bondar NP, Migdal SD, Simonian SK, Monforte JR, McDonald FD, Harness JK, Cole KL. Epidemic methanol poisoning: Clinical and bio-chemical analysis of a recent episode. Medicine 1981;60:373-82.

3. Chow MT, DiSilvestro VA, Yung CY, Nawab ZM, Leehey DJ, Ing TS. Treatment of acute methanol intoxication with hemodialysis using an ethanol-enriched, bicarbonate-based dialysate. Am J Kidney Dis 1997;30:568-70.

4. Wadgymar A, Wu GG. Treatment of acute methanol intoxication with hemodialysis (letter). Am J Kidney Dis 1998;31: 897.

5. Sargent JA, Gotch FA, Lam M, Prowitt M, Keen M. Technical aspects of on-line proportioning of bicarbonate dialysate. Proc Clin Dial Transplant Forum 1977;7:109-16.

6. Delin K, Attman PO, Dahlberg M, Aurell M. A clinical test of a new device for on-line preparation of dialysis fluid from bicarbonate powder-The Gambro BiCart. Dial Transplant 1988;17:468-82. 